\title{
Video-imaging of transient rip currents on the Gold Coast open beaches
}

\author{
Thomas Murray $\dagger$, Nick Cartwright $\uparrow$, Rodger Tomlinson \\ $†$ School of Engineering, Griffith \\ University, Southport, QLD, 4215, \\ Australia \\ t.murray@griffithuni.edu.au \\ n.cartwright@griffith.edu.au \\ $\ddagger$ Griffith Centre for Coastal \\ Management, Griffith University, \\ Southport, QLD, 4215, Australia \\ r.tomlinson@griffith.edu.au
}

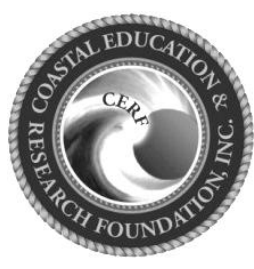

www.cerf-jcr.org

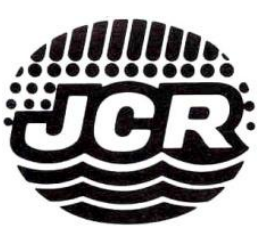

www.JCRonline.org

ABSTRACT

Murray, T., Cartwright, N., Tomlinson, R., 2013. Video-imaging of transient rip currents on the Gold coast open beaches. In: Conley, D.C., Masselink, G., Russell, P.E. and O'Hare, T.J. (eds.), Proceedings $12^{\text {th }}$ International Coastal Symposium (Plymouth, England), Journal of Coastal Research, Special Issue No. 65, pp. 1809-1814, ISSN 0749-0208.

This paper reports on the first video analysis of transient rip behaviour in the Southern Hemisphere. Transient rips were identified from a high camera located approximately $100 \mathrm{~m}$ above mean sea level at Narrowneck, Gold Coast, Australia. Transient rip occurrence, duration and flow behaviour were identified from the video and occurrence was correlated with environmental factors including beach state, wave, tide and wind characteristics. Transient rips were found to display a mushroom cloud rip head and a narrow trailing rip neck consistent with characteristics often displayed by topographically controlled rips. Transient rip events were characterised by short life-spans $(30-236 \mathrm{~s})$ and low temporal frequency, but high temporal variance, occurring for only $0.52 \%$ of the time in the video. Around $68 \%$ of transient rip events identified occurred when the beach was generally alongshore uniform in a shore-attached terrace state. During terrace beach conditions, transient rip occurrence was found to be significantly greater on the ebb tide as opposed to the flood tide. There was no significant difference with transient rip occurrence between the ebb and flood tide under bar-trough beach state conditions. Transient rip occurrence was significantly greater when wave breaking was absent on the outer bar for both terrace and bar-trough beach states. There was a lack of a clear correlation between averaged wave and wind conditions and transient rip formation. Current and future study is focussing on the effects of wave groupiness and sea state on transient rip occurrence, spacing, duration and intensity.

ADDITIONAL INDEX WORDS: Beach state, rip activity, morphodynamics.

\section{INTRODUCTION}

Despite a recent review by Dalrymple et al. (2011) of the possible causes or types of transient rip currents in the surf zone, there is still no consensus on the definition of a transient rip current in the literature or the professional (i.e. lifeguards and beach managers) world. It is commonly accepted that transient rips vary in location and occurrence making them hard to predict, and are controlled by surf zone hydrodynamics rather than beach and surf zone morphology and / or topography (Johnson and Pattiaratchi, 2006). It is generally believed that they tend to occur on fairly uniform planar beaches with a Low Tide Terrace (LTT) beach state and a shore-attached bar (Murray et al., 2003, Johnson and Pattiaratchi, 2004). Transient rips are hazardous to the public as they can move bathers from shallow to deep water rapidly.

The radiation stress of the incoming wave field is the fundamental driver of pressure gradients and thus wave-driven currents in the nearshore zone. The hypothesis behind the formation of transient rip features is that the radiation stress field is spatially and temporally variable, due to variations in the timeaveraged wave field, leading to incipient currents which occur in differing locations, have a short-lifespan and then decay (Murray et al., 2003, MacMahan et al., 2006, Johnson and Pattiaratchi, 2006). Variations in wave height and breaking patterns in the incoming wave field can be topographically or hydrodynamically controlled. Transient rips are assumed to be hydrodynamically

DOI: 10.2112/S165-306.1 received 07 December 2012; accepted 06 March 2013.

(c) Coastal Education \& Research Foundation 2013 controlled, albeit they may be influenced by small bathymetric non-uniformities. Temporary currents may arise where there is increased setup locally, driving strong pressure gradients and accelerating the water particles into the depressed region of the water surface. Whilst variations in radiation stress typically occur at incident wave frequencies (gravity waves), pressure gradients can also be generated by lower frequency motions of non-gravity waves (e.g. wave-groups) (MacMahan et al., 2004a, MacMahan et $a l ., 2010)$. It is hypothesised that rip currents are driven by the time-averaged pressure/radiation stress gradients and therefore the time-scale of their variation and pulsing tends to respond to wave groups.

Previous studies showed that transient rips are likely to form on a gentle sloped beach faced with moderately energetic wave conditions (Johnson and Pattiaratchi, 2004; Johnson and Pattiaratchi, 2006, Murray et al., 2003, Slattery, 2010). For relatively shore normal wave conditions it is hypothesised that wave-to-wave interactions and wave groupiness play a role in the local formation of transient rip currents (Johnson and Pattiaratchi 2004, Johnson and Pattiaratchi, 2006, MacMahan et al., 2004a, MacMahan et al., 2004b, MacMahan et al., 2010, Dalrymple et al., 2011). For oblique waves conditions, shear instabilities in the longshore flow are thought to be the governing mechanism driving transient rip formation (Bowen and Holman, 1989, Özkan-Haller and Kirby, 1999, Dalrymple et al., 2011). There is little evidence in the literature to support these hypotheses and as such ongoing research into these spatially and temporally variable currents is required. 


\section{Video-imaging}

Video-imaging studies from a high mounted camera with a wide view of the beach and surf zone have become increasingly important in the study of surf zone morphodynamics in the last 20 years. The ARGUS system was the first such system to use a timeexposure video technique developed by Lippmann and Holman (1989) to quantify the study of temporal and spatial variability of sand bar morphology. The Coastal Conditions Monitoring System (CoastalCOMS) is an automated observation system for coastal monitoring being developed by Coastalwatch (Williams, 2009). The system is comprised of a shore-mounted video camera network and sophisticated image processing routines for analysis and display of coastal environment information (Williams, 2009). A major benefit of video camera data is that the same information as manual surf zone instrument data can be collected on a much larger scale and on a continual basis. As a direct result a much more accurate description of spatial and temporal changes to a beach system can be derived.

This paper reports on the first video analysis of transient rip behaviour in the Southern Hemisphere. Capturing these spatially and temporally variable currents in the surf zone is extremely difficult using both Lagrangian and Eulerian techniques. The strong visual clues (e.g. plumes of sediment-laden water extending offshore) of transient rip currents makes them readily accessible for study by camera techniques.

\section{Aims}

The paper seeks to explore transient rip occurrence and duration under a variety of beach state, wind, wave and tidal conditions. Whilst it is hypothesised that transient rip formation is fundamentally driven by small scale spatial and temporal variations in the incoming wave field and thus related to changes in the radiation stress gradients, simple parametric statistical tests are used to assess likely conditions which may favour transient rip development.

\section{METHODS}

\section{Study Site}

The Gold Coast is located on the East Coast of Australia around $28^{\circ} \mathrm{S}$ (Figure 1a). The typical open ocean Gold Coast beach is microtidal, exposed to a highly variable wave climate and typically presents a double-barred system with bar and trough topography and experiences a net northward littoral drift (Strauss et al., 2006).

The Main Beach - Narrowneck study site (Figure 1a) is composed of generally fine sand to produce a wide, low gradient high tide beach fronted by a 150 to $200 \mathrm{~m}$ wide surf zone (Short, 2000). Modal beach state conditions at the study site are: a Low Tide Terrace (LTT) / Transverse Bar Rip (TBR) inner bar and a Rhythmic Bar Beach (RBB) outer bar (Short, 2000). The inner and outer bar at the study site are, topographic rip dominated and transient rip occurrence is less common.

\section{Experimental Methods}

\section{Video monitoring}

Transient rips were identified from a vertical camera located approximately $100 \mathrm{~m}$ above mean sea level at Narrowneck, Gold Coast, Australia. The camera spans through three views for analysis, giving an almost $180^{\circ}$ view of a $1.1 \mathrm{~km}$ stretch of coastline (Figure 1b). The camera records continuous video footage at a rate 15.9 frames per second. Transient rip occurrence, duration (approximated in seconds) and flow behaviour were identified from the video and occurrence was correlated with environmental factors including beach state, wave, tide and wind characteristics. Transient rip occurrence for each beach state was weighted by the percentage of beach state occurrence. The parameter 'rip activity' (RA) was calculated to compare to Slattery's (2010) results from Long Island, New York. Rip activity was defined to be the sum of rip current duration (hr) per length of shoreline $(\mathrm{km})$ divided by the total time of observation $(\mathrm{hr})$.

Transient rips were identified forming off the shore-attached bar
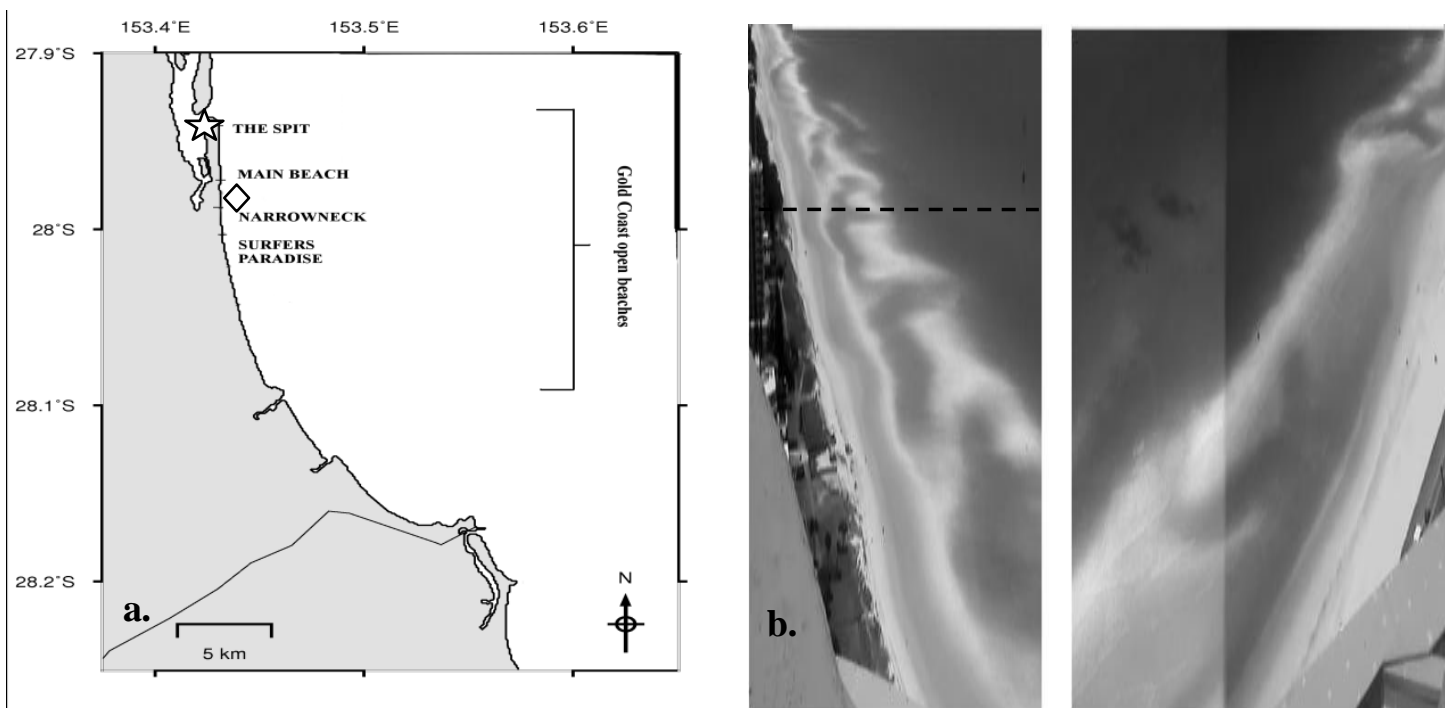

Figure 1. Study site: (a) Map of the Gold Coast open beaches. Wind data collected from a weather station at the Spit (star), Wave data collected in $16 \mathrm{~m}$ of water (diamond); (b) Camera views for the Main Beach to Narrowneck study site. There is an approximate $400 \mathrm{~m}$ black spot directly below the camera, displayed by the white gap. The dashed line indicates the northward limit of the study area. 
(Figure 2), with the offshore bar(s) ignored as it is too difficult to resolve small scale topographic non-uniformities on the offshore bar(s). If the inner bar was not shore-attached i.e. in a Rhythmic Bar Beach (RBB) state, the shore-attached bar or beach was always in a terrace state (even when displaying slight rhythmic morphology) and transient rips were identified off the beach terrace. During periods of transitional TBR/RBB morphology transient rips were identified in areas where the inner bar was shore-detached (i.e. in a more RBB state). Once again the transient rips were observed occurring off the beach terrace. Transient rips were differentiated from topographic rips using low tide timeximaging of the beach. Daily timex images are created by the CoastalCOMS cameras at low, mid and high tide. Beach state was classified from timex images.

A 399 day sample period was analysed. The video sampling was biased for days where transient rip formation was expected based on knowledge from the literature, professional lifeguards and coastal geomorphologists. Days when the inner bar-beach was shore-attached and / or in a terrace state were favoured, with high energy wave conditions and prolonged periods of well-developed TBR morphology generally ignored. 20 percent of days analysed saw TBR beach morphology with no transient rips identified on those days (cf. results and discussion sections).

799 hours of daily video footage $(10-12$ hours continuous footage each day) was sampled to analyse transient rip frequency and duration. An additional 230 hours of 5 minute video recordings were analysed (where daily video was absent) for rip duration.

\section{Environmental parameters}

Half hourly wave data was obtained from a nearby directional waverider (Figure 1a). Half hourly average wind data was obtained from a nearby automatic weather station (Figure 1a). Tide data is collected from the Bureau of Meteorology tidal predictions, at the entrance to the Gold Coast Seaway (The Spit).

\section{PRELIMINARY RESULTS}

\section{Qualitative Description of Transient Rip Evolution}

Rip features can be visually identified in the video by sediment laden and/or turbulent foamy water, moving offshore. Transient rips generally formed as a 'mushroom cloud' rip head pulsing offshore, trailed by a narrow rip neck (Figure $2 \mathrm{a}$ ) or occasionally a rip neck formed with no obvious rip head (Figure 2b). During conditions when an alongshore current was present, the rips migrated in the direction of the dominant alongshore water movement. $73.58 \%$ of transient rips identified for occurrence were qualitatively observed to migrate, whilst $26.42 \%$ were relatively stationary. Transient rips were seen to pulse both once or multiple times during their evolution. On termination, the rip head detached from the rip neck, shedding further offshore before dissipating, with termination proposed to be induced by bottom friction and lateral mixing.

Evolution of the observed transient rips was found to be similar to that qualitatively described by Vos (1976) and was consistent with Johnson and Pattiaratchi's (2006) conceptual model of transient rip formation. Johnson and Pattiaratchi (2006) suggest that local generation of vorticity by longshore variability of wave breaking leads to the formation and offshore propagation of a vortex pair, which is intensified by vortex stretching and the formation of a trailing and reinforcing rip neck. They also conceptualised the observed detachment and shedding of the rip head offshore and dissipation of the rip current.

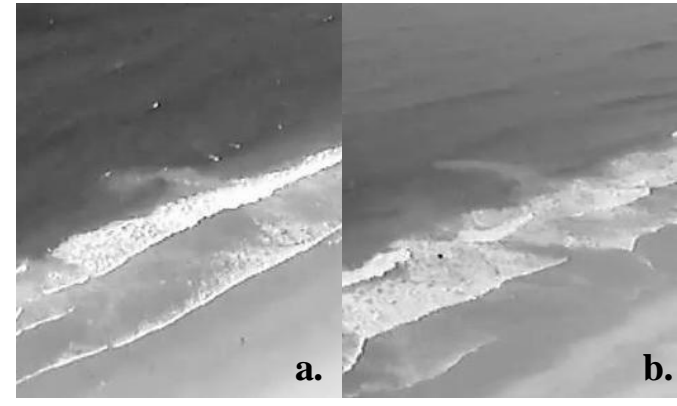

Figure 2. Two examples of transient rips occurring at Narrowneck, Gold Coast, Australia.

\section{Rip Activity and Occurrence}

217 individual rips were identified from the 799 hours of daily video footage. However of those 217, 24 (11\%) were associated with a small bathymetric non-uniformity (e.g. holes, mega-ripples, relic rip channels) and as such were ignored from the analysis. Two of the transient rips were forming as the camera view changed so an accurate analysis of duration for these two rips is unattainable.

A transient rip signal was present for 4.17 hours in the daily video footage, with transient rips occurring for $0.52 \%$ of the total time (Table 1). Around 2 rips were observed per kilometre per day, with low levels of transient rip activity (RA) for the duration of the study period (Table 1).

$68.35 \%$ of transient rips were observed under terrace beach conditions (LTT and LTT/TBR transitional state) with the inner bar welded to the beach (Figure 3). 25.11\% of the time transient rips were observed when the inner bar was detached (RBB and RBB/LBT morphology) and only $6.52 \%$ of transient rips occurred when the inner bar was semi-attached (TBR/RBB transitional state) with transient rips still occurring off the beach terrace inside areas where the inner bar was shore-detached (Figure 3). No transient rips were observed when the beach was in a Transverse Bar Rip state (TBR) (Figure 3).

\section{Rip Duration}

An additional 42 individual transient rips were identified in the extra 230 hours of 5 minute video recordings for duration analysis.

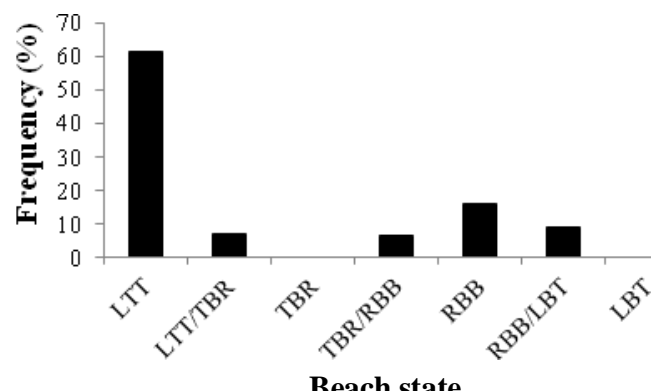

Figure 3. Weighted transient rip occurrence (\%) vs. beach state $(n=193)$. The frequency of rip occurrence is weighted for the percentage of beach state occurrence. 
Table 1. Transient rip occurrence and activity statistics

\begin{tabular}{lr}
\hline Video Observed (hr) & 799 \\
Individual Transient Rip Events & 193 \\
Frequency (\%) of Transient Rip Signal Evident in Video & 0.52 \\
Rips / km / day & 2.17 \\
Rip Activity (n = 233) $\left(\mathrm{km}^{-1}\right)$ & 0.0047 \\
& \\
Table 2. Transient rip duration statistics & 1029 \\
\hline \hline Video Observed (hr) & 233 \\
Individual Transient Rip Events & 82.75 \\
Average Rip Duration (s) & 60 \\
Modal Rip Duration (s) & 30 \\
Minimum Duration (s) & 236 \\
Maximum Duration (s) & 33.36
\end{tabular}

A total of 233 individual transient rips were analysed for duration. An average duration of $82.75 \mathrm{~s}$ was recorded with a large standard deviation of the mean (Table 2). Modal duration was $60 \mathrm{~s}$ and no rips lasted longer than $240 \mathrm{~s}$ (Table 2). $58.37 \%$ of transient rips identified lasted between $60-90 \mathrm{~s}$ with only $3.00 \%$ lasting between 180 to $240 \mathrm{~s}$ (Figure 4).

\section{Statistical Analysis Results}

No strong correlations were found to occur between transient rip occurrence and any of the half hour averaged wave or wind conditions. This was also found to be true when analysing terrace (LTT and LTT/TBR); and bar-trough (TBR/RBB, RBB and $\mathrm{RBB} / \mathrm{LBT}$ ) beach states separately, with individual wind and wave parameters showing no significant correlation with transient rip occurrence. As such, a Generalised Additive Model (Wood, 2006) is currently being derived from the data to further investigate relationships between environmental conditions and transient rip occurrence.

Statistical significance was assessed using an independent t-test which revealed that a significant effect for outer bar activity was found for terrace beach states, $t(272.98)=6.06, \mathrm{p}<0.001$ and bartrough beach states $t(417.67)=4.68, \mathrm{p}<0.001$, with a greater number of transient rips occurring when there was no wave breaking on the outer bar as opposed to when wave breaking was present. A significant effect of tide stage was found for terrace beach states, $t(330.73)=4.96, \mathrm{p}<0.001$, with a greater number of transient rips occurring on the ebb tide compared with the flood tide. There was no significant difference in transient rip

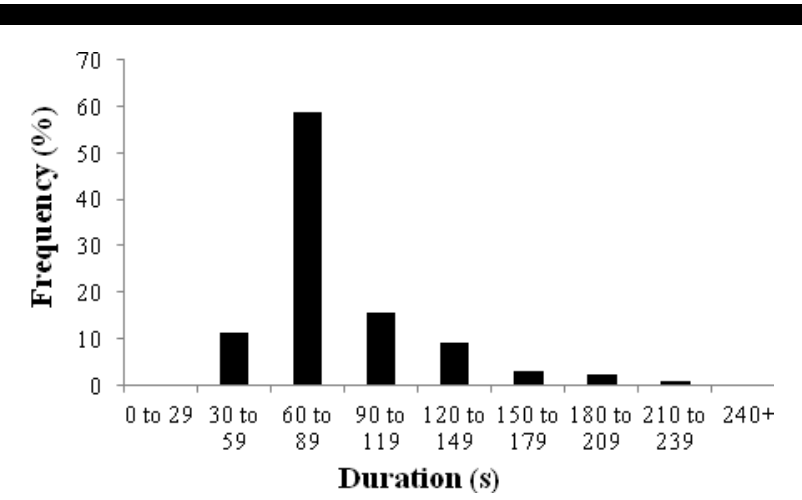

Figure 4. Frequency distribution (\%) of transient rip duration (n $=233$ ) occurrence on the ebb or flood tide under bar-trough beach state conditions, $t(1141.98)=0.42, \mathrm{p}=0.67$

Transient rips were found to occur throughout most of the tidal cycle under terrace beach conditions, favouring the ebb and low tide (Figure 5). Transient rips during bar-trough inner bar conditions favoured the high tide and did not occur around the low tide (Figure 5).

\section{DISCUSSION}

The preliminary results show transient rip occurrence to be infrequent, spatially and temporally variable, with no obvious correlations between occurrence and averaged wave and wind conditions. The wind and wave data used had been averaged over 30 minute intervals, whereas the transient rips have a life time scale of the order of tens of seconds to minutes before decaying. This highlights the fact that transient rip events are more likely to be induced by short-lived spatial and temporal variations in the surf zone wave field (e.g. wave groups) and do not tend to favour any particular averaged swell or wind conditions.

Changes in beach and surf zone morphodynamics over a tidal cycle will result in dynamic and variable changes in transient rip occurrence with significantly more rip events occurring on the ebb tide than the flood tide during terrace beach conditions. This is consistent with the understanding of topographically controlled rip currents. The result may reinforce the idea that some sort of small bathymetric perturbation contributes to the offshore flow. Traditionally topographic beach rip currents increase in velocity during falling to low water conditions due to nearshore bar morphology becoming increasingly shallow and offshore flows being confined to rip channels (Short, 2007). The tide level will also directly affect the water depths in the nearshore zone and the intensity of wave breaking, which supports Nielsen et al. (2001) concept of rip currents responding to the efficiency of the wave pump.

It is hypothesised that the increased prevalence of transient rips on the falling and low tides during LTT beach states may be due to the increased influence of shear instabilities in the longshore current, creating temporary offshore jets of water. Previous field studies have observed significant meandering of strong alongshore currents; driven by obliquely incident waves (Oltman-Shay et al., 1989, Özkan-Haller and Kirby, 1999, Dalrymple et al., 2011). The presence of strong shear in the alongshore current cross-shore profile can lead to shear instability and the meandering of the alongshore current in the cross-shore direction (Bowen and Holman, 1989, Özkan-Haller and Kirby, 1999, Dalrymple et al., 2011).

It was qualitatively observed during the days of LTT beach state and high transient rip occurrence that oblique wave angle would generate a shore parallel longshore current and cross-shore flows that migrate in the direction of the alongshore current. It is commonly accepted that, like topographically controlled rip currents, longshore current speeds are increased on the falling and low tide as more intense wave breaking and hence stronger radiation stress gradients develop over the bar. The increased power of the hydrodynamic forcing over the mostly alongshore planar beach, may lead to an increase in shear instabilities, creating offshore flows on the falling and low tide.

This may also explain the lack of transient rips occurring on the low tide under bar-trough beach state conditions, with less of an influence of longshore current instabilities generating offshore flows and more influence of localised wave modification, creating transient rips.

The result showing a significant amount more rips occurring when there is an absence of wave breaking on the outer bar is 


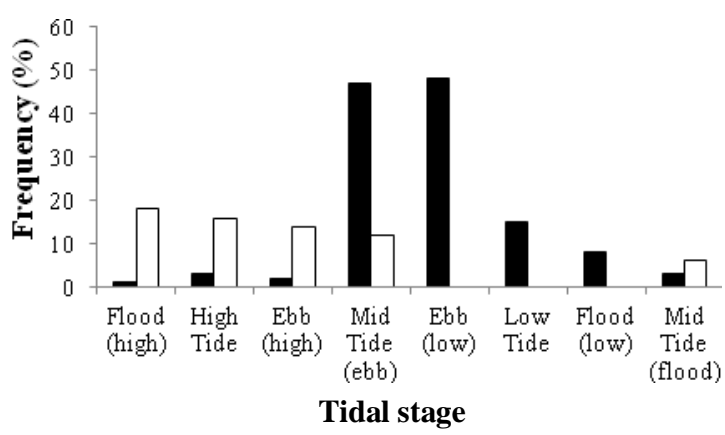

Figure 5. Frequency distribution (\%) of transient rip occurrence for tidal stage. Terrace beach state $(\boldsymbol{m}) \mathrm{n}=127$; Bar-trough beach state $(\square) \mathrm{n}=66$.

expected. As all transient rips recorded were measured off the shore-attached terrace / beach, this result is attributed to wave energy dissipation on the outer bar limiting transient rip formation inshore, due to a lack of significant wave energy inshore to create short-lived currents. Additionally, although there is no wave breaking on the outer bar the incoming wave field is still influenced by the bar through shoaling and refraction processes which may lead to a more variable inshore wave field. This in turn would create spatial and temporal variations in the radiation stress gradient which drive the transient currents. This hypothesis is supported by the finding that the majority of the transient rips forming under bar-trough inner surf zone morphology, occur around the high tide. Future work with wave spectra and surf zone current data is required to further evaluate these hypotheses.

Low rip current activity and rip occurrence (Table 1) is consistent with results of Slattery (2010), who measured rip activities of $1.44 \mathrm{E}^{-06}$ and $4.65 \mathrm{E}^{-04}$ at their study sites respectively. Slattery (2010) conducted the only other similar study to date on transient rips at two sites on Long Island, New York. Long Island is a $190 \mathrm{~km}$ long stretch of mostly continuous coastline cut by seven inlets (Slattery, 2010). As with the Gold Coast the Long Island beaches are microtidal and present a similar wave climate with average wave conditions around $1 \mathrm{~m}$ with wave periods of around $7 \mathrm{~s}$ and maximum wave heights of around $3.5 \mathrm{~m}$ with periods of $12-14 \mathrm{~s}$ during storm conditions (Slattery, 2010). Slattery (2010) found transient rips persisting for less than $1 \%$ of the time in their video at both locations, which is consistent with this study. They also measured similar average (47 and $76 \mathrm{~s}$ ), maximum (150 and $180 \mathrm{~s})$ and minimum (20 and $30 \mathrm{~s})$ rip durations at their two study sites. One of the sites on Long Island saw two rips per kilometre per day occurring, which is consistent with this study, whilst the other site saw 13 rips per kilometre per day.

The rips do tend to favour and become more dominant under low tide terrace conditions (Figure 3). As the influence of topographically controlled rip channels increases (under RBB and TBR beach states) transient rip occurrence tended to decrease, suggesting that the pressure gradient forcing over the bar/rip morphology over-rides the smaller spatial and temporal variations in wave set-up and set-down, which may lead to the formation of transient rip currents.

Whilst transient rips are present, they are clearly not the dominant offshore process occurring on the Gold Coast open beaches, with 'fixed' rip currents (channels) providing the main driving mechanism for moving sediment and floatsam beyond the surf zone. Transient rips and topographically controlled fixed rips were observed to coexist (Figure 3), with the topographically controlled currents dominating the rip current pulsing. It is important to note that no transient rips were observed under strongly formed TBR conditions, as the topographically controlled rip currents dominate the offshore hydrodynamic processes (Figure 3).

The short-lived nature of the offshore directed currents, migration with the alongshore current and lack of clear bathymetric perturbations in the low tide timex-images suggests that these temporary events are driven by hydrodynamics rather than beach and surf zone morphology. Whilst they seem to be forced by hydrodynamics, it is difficult to rule out the influence of small bathymetric non-uniformities on the evolution of these temporary currents. Occasionally more than one transient rip formed at the same time and tended to have similar durations, which also supports the hypothesis that they are fundamentally induced by changes in the incoming wave field as opposed to beach and surf zone morphology.

\section{Limitations of Methods}

The CoastalCOMS camera that produces the video for the study is set up on a pre-existing tour as it is primarily used for other coastal engineering purposes. The camera switches between the three views every $60-300 \mathrm{~s}$ as necessary for its other engineering purposes. All of the 5 minute video recordings were stationary on each view for the full 300 seconds. Whilst this limitation has implications for the accuracy of the frequency and duration data, the method is able to depict a solid approximation of transient rip occurrence and due to the short life span of the currents provide a general approximation of rip current duration in the study region statistically. Glare on the water surface, particularly in the winter months makes it difficult to resolve the transient rip signal in the video at certain times of the day / year. At its worst 20 minutes of video footage a day for 55 days of the sample period ( $2 \%$ of the total video) is affected by glare on the water surface, with low confidence on resolving transient rip activity. Wind conditions may also affect the transient rip signal in the video with a stormy sea state making the surf zone 'messier' and thus more difficult to identify transient rip occurrence. In saying this it is proposed that transient rip formation tends to favour more plunging type breakers so when winds are strong onshore, waves tend toward the more spilling type and transient rip occurrence may in fact be inhibited or limited.

\section{Future Work}

The complexity of the morphodynamic and physical processes involved in transient rip formation suggest further investigation is required to provide a better understanding of conditions under which transient rip occurrence is favoured.

A generalised additive model (GAM) is currently being derived based on the data to further explore the effect of a suite of predictor variables (wave, wind, tide and beach state) potentially influencing the response variable (transient rip occurrence). GAMs enable flexible specification of the dependence of a response variable on the predictor variables without having to specify the model in terms of detailed parametric relationships (Wood, 2006). This type of statistical analysis looks at relationships between all the predictor variables (i.e. the environmental conditions) and the response variable. The GAM analysis can then be used to provide a multivariate assessment of transient rip occurrence whilst also accounting for potential nonlinearity in the physical relationships. The GAM provides a more sophisticated statistical interpretation of the data than simple parametric analysis. A preliminary GAMs analysis incorporating 
the half hour averaged wave and wind data as well as tide, beach state and outer bar activity data has been undertaken (results not presented here) to assess transient rip occurrence as a function of these physical predictors. Preliminary results appear encouraging.

In future, image rectification and a spatial analysis of transient rip occurrence will be undertaken to determine: spacing, preference of location and intensity (i.e. how far offshore the currents reach before dissipating). The results of this will also be correlated to environmental factors using a combination of univariate and multivariate (in particular a GAMs assessment) statistics to determine whether there are any strong relationships between rip spacing and intensity and the environmental conditions. Image rectification will also be used to further assess the behaviour of migrating as well as stationary rips.

Other future work includes an analysis of sea state and wave groupiness. It is hypothesised that a stochastic sea state, with more than one swell or sea present in the water may lead to an increase in transient rip occurrence, due to the increased spatial and temporal variability of the incoming wave field. The directional spectrum of the incoming wave field on the Gold Coast is often bimodal (i.e. swell from one direction and sea from another). This study therefore promotes an analysis of sea state and wave groupiness to be compared with transient rip occurrence.

\section{CONCLUSIONS}

The physical characteristics of transient rips observed on the Gold Coast open beaches are consistent with the literature, with rip currents displaying a mushroom cloud rip head and a narrow trailing rip neck (Vos, 1976, Johnson and Pattiaratchi, 2006, Slattery, 2010). Transient rip events are characterised by short life-spans $(30-236 \mathrm{~s})$ and low temporal frequency, but high temporal variance, occurring for only $0.52 \%$ of the time in the video. This has implications for hazard management as they tend to be more random and short-lived events which have the potential to move bathers from shallow to deep water rapidly. This makes the transient rip hazard more difficult to mitigate than the more 'fixed' topographic beach rip hazard.

Transient rips are not the most dominant rip current type existing on the Gold Coast open beaches, but their occurrence and influence on beach morphodynamics and hazards is increased when the beach is in a low energy LTT state, with the bar and beach planar and mostly uniform. It is hypothesised that transient rip formation under planar terrace beach state conditions may be due to the increased influence of shear instabilities in the longshore current creating temporary offshore jets of water. Meanwhile localised wave modification is thought to be the fundamental driver of transient rips under bar-trough morphology conditions. Further analysis using wave spectra and current data is required to investigate these two hypotheses. As there has been a lack of clear correlations between averaged wave and wind conditions and transient rip formation with the present data, the study promotes a higher frequency temporal scale analysis correlating video to high frequency $(4-8 \mathrm{~Hz})$ pressure gauges and ADCP's deployed in the surf zone or just beyond the surf zone to measure waves and currents. This will provide an analysis of wave groupiness and sea state to be compared with transient rip occurrence, spacing, duration and intensity.

\section{ACKNOWLEDGEMENTS}

We would like to thank CoastalCOMS for providing the infrastructure for video and data collection. Wave data was supplied by DEHP and Gold Coast City Council. Wind and tide data was supplied by the Bureau of Meteorology.

\section{LITERATURE CITED}

Bowen, A. J. and Holman, R. A. 1989. Shear instabilities of the mean longshore current. Journal of Geophysical Research, 94, 18023-18030

Dalrymple, R. A., MacMahan, J. H., Reniers, A. J. H. M and Nelko, V, 2011. Rip currents. Annual Review of Fluid Mechanics, 43, 551-581.

Johnson, D. and Pattiaratchi, C. 2004. Transient rip currents and nearshore circulation on a swell-dominated beach. Journal of Geophysical Research, 109, C02026.

Johnson, D. and Pattiaratchi, C., 2006. Boussinesq modelling of transient rip currents. Journal of Coastal Engineering, 53, 419439.

Lippmann, T.C. and Holman, R. A., 1989. Quantification of sand bar morphology: a video technique based on wave dissipation. Journal of Geophysical Research, 94, 955-1011.

MacMahan, J., Reniers, A., Thornton, E. and Stanton, T., 2004a Surf zone eddies coupled with rip current morphology. Journal of Geophysical Research. C Oceans, 109:C07004, pp. 15.

MacMahan, J., Reniers, A., Thornton, E. and Stanton, T., 2004b. Infragravity rip current pulsations. Journal of Geophysical Research, 109, C01033.

MacMahan, J. H., Thornton, E. B. and Reniers, A. H. M., 2006. Rip current review. Journal of Coastal Engineering, 53, 191208.

MacMahan, J. H., Reniers, A. H. M. and Thornton, E. B., 2010. Vortical surf zone velocity fluctuations with $0(10)$ min period. Journal of Geophysical Research, 115:C06007, pp. 18.

Murray, A. B., Lebars, M. and Guillon, C., 2003. Tests of a new hypothesis for nonbathymetrically driven rip currents. Journal of Coastal Research, 19, 269-277.

Nielsen, P., Brander, R. W. and Hughes, M. G., 2001. Rip currents: observations of hydraulic gradients, friction factors and wave pump efficiency. In: Hanson, H. and Magnus, L. (eds.), Proceedings of the Fourth Conference on Coastal Dynamics '01, Lund, Sweden, 483-492.

Oltman-Shay, J., Howd, P. and Birkemeier, W. 1989. Shear instabilities of the mean longshore current, 2. Journal of Geophysical Research, 94, 18031-18042.

Özkan-Haller, H. T. and Kirby, J. T. 1999. Nonlinear evolution of shear instabilities of the longshore current: a comparison of observation and computations. Journal of Geophysical Research, 104, 25953-25984.

Short, A. D., 2000. Beaches of the Queensland Coast: Cooktown to Coolangatta: a guide to their nature, characteristics, surf and safety. Sydney: Coastal Studies Unit, 360 p.

Short, A. D., 2007. Australian rip systems - Friend or foe? Journal of Coastal Research, Special Issue No. 50, 7-11.

Slattery, M. P., 2010. Assessing the nature of rip currents along the south shore of Long Island, NY: Dominant rip type and insights into possible forcing mechanisms. New York, USA: Stony Brook University, Ph. D. thesis, 128p.

Strauss, D., Tomlinson, R. and Hughes, L., 2006. Numerical modelling and video analysis of intermediate beach state transitions. The $7^{\text {th }}$ International Conference on Hydroscience and Engineering (Philadelphia, USA), ICHE, 14p.

Vos, R. G., 1976. Observations of the formation and location of transient rip currents. Sedimentary Geology, 16, 15-19.

Williams, P., 2009. CoastSAFE Alive - Water Safety Systems Literature Review. Griffith Centre for Coastal Management Research Report No. 93 -2, Gold Coast: Griffith University, $36 \mathrm{p}$.

Wood, S., 2006. Generalized Additive Models. An Introduction with R. Boca Raton, Florida: Chapman and Hall, $410 \mathrm{p}$ 